\title{
Induction differentiation of rabbit adipose-derived stromal cells into insulin-producing cells in vitro
}

\author{
YU SUN $^{1}$, MENGCHAO ZHANG $^{2}$, SHANGWEI JI ${ }^{3}$ and LIN LIU ${ }^{2}$ \\ Departments of ${ }^{1}$ Intervention, ${ }^{2}$ Radiology and ${ }^{3}$ Gastroenterology, \\ China-Japan Union Hospital of Jilin University, Changchun, Jilin 130033, P.R. China
}

Received October 30, 2014; Accepted July 17, 2015

DOI: $10.3892 / \mathrm{mmr} .2015 .4305$

\begin{abstract}
Mesenchymal stem cells (MSCs) with the ability to differentiate into insulin-producing cells (IPCs) have become the most promising means of therapy for diabetes mellitus. Adipose-derived stromal cells (AdSCs), having similar characteristics to those of derived MSCs, are known to exhibit extensive proliferation potential and are able to undergo multi-lineage differentiation. Whether AdSCs can differentiate into insulin-producing cells (IPCs), however, has not been sufficiently elucidated. Therefore, the present study sought to investigate the in vitro differentiation of rabbit (r)AdSCs into IPCs, which may provide an abundant source of cells to treat diabetes. rADSCs were obtained from liposuction aspirates and then induced with glucagon-like peptide- 1 and nicotinamide to differentiate into insulin-secreting cells. Differentiation was evaluated by the analysis of morphology, dithizone (DTZ) staining, reverse transcription polymerase chain reaction (RT-PCR), western blot analysis and a glucose challenge assay with detection of insulin secretion by ELISA. Morphological phase-contrast microscopic observation revealed typical islet-like cell clusters following 21 days of differentiation. DTZ staining also showed that differentiated cells were positive and undifferentiated cells were negative for insulin production. Furthermore, RT-PCR analysis confirmed the mRNA expression of insulin, PDX1 and GLUT2 in differentiated cells. Western blot analysis showed that insulin was expressed by the differentiated cells. The glucose challenge assay showed that insulin secretion of the IPCs was in a glucose dependent manner. These findings implied that AdSCs are able to differentiate into IPC in vitro, and are therefore promising candidates for the treatment of diabetes.
\end{abstract}

Correspondence to: Professor Lin Liu, Department of Radiology, China-Japan Union Hospital of Jilin University, 126 Xiantai Street, Changchun, Jilin 130033, P.R. China

E-mail: liulin54328@126.com

Key words: adipose-derived stromal cells, insulin-producing cells, differentiation

\section{Introduction}

Diabetes mellitus (DM) is a heterogeneous group of metabolic disorders characterized by hyperglycemia with impaired metabolism of carbohydrate, fat and proteins as a result of defects in insulin secretion and/or insulin action $(1,2)$. The incidence of diabetes has been steadily increasing and is expected to rise to 439 million adults in 2030 worldwide (3). Type 1 diabetes (T1D) is a T cell-mediated autoimmune disorder caused by decreased insulin production due to destruction of insulin-secreting $\beta$-cells in pancreatic islets (4-6). Although transplantation of islets of Langerhans has recently been suggested to be an efficient cell-based therapy for T1D, the outcome has remained poor due to the risk of immunological rejection as well as rareness of donors (7-9). Therefore, it is required to identify novel renewable sources for expanding pancreatic islets.

A growing number of stem cell biological studies have suggested that somatic stem cells, i.e. mesenchymal stem cells (MSCs), including bone marrow and adipose stromal progenitor cells, have potential therapeutic value for DM $(10,11)$. Since MSCs, particularly MSCs from bone marrow (BMSCs), have the potential for multiple passages in culture and differentiation into various cell types, including endocrine cells of the pancreas (12), they are particularly promising for use in the treatment DM. BMSCs have been evidenced to have therapeutic value in the treatment of T1D due to their potential for differentiation into insulin-secreting cells and their immunomodulatory properties $(6,13,14)$. Although adipose-derived stromal cells (AdSCs) share a number of characteristics with BMSCs, which have the ability to proliferate and differentiate into a variety of cell types (15), it has largely remained elusive whether AdSCs can differentiate into insulin-producing cells (IPCs). Thus, the present study aimed to investigate the ability of the rabbit (r)AdSCs to differentiate into IPCs, which may offer a potentially effective therapeutic approach in cell therapy of DM.

\section{Materials and methods}

Isolation and culture of AdSCs. In total, three male New Zealand White rabbits (weight, 2-3 kg) were purchased from the Experimental Animal Center of Changchun Biological Institute (Changchun, China) and maintained in specific 
pathogen-free conditions. Rabbits were sacrificed by cervical dislocation. Subcutaneous adipose tissues of the inguinal region were harvested using scissors under sterile conditions. To remove red blood cells and tissue debris, adipose tissue was washed with an equal volume of sterile phosphate-buffered saline (PBS) containing $1 \% 100 \mathrm{U} / \mathrm{ml}$ penicillin, or $100 \mathrm{mg} / \mathrm{ml}$ streptomycin (Gibco Life Technologies, Carlsbad, CA, USA). Washed tissue fragments were digested with $0.075 \%$ collagenase II (Sigma-Aldrich, St. Louis, MO, USA). The cell density was adjusted to $1 \times 10^{5} / \mathrm{ml}$ and cells were plated in $100-\mathrm{cm}^{2}$ tissue culture flasks in low-glucose Dulbecco's Modified Eagle Medium (LG-DMEM; Gibco-BRL, Invitrogen Life Technologies, Inc. Carlsbad, CA, USA) supplemented with $10 \%$ fetal bovine serum (FBS; Sigma-Aldrich). Cells were cultured in an incubator at $37^{\circ} \mathrm{C}$ in a humidified atmosphere containing 5\% $\mathrm{CO}_{2}$ and medium was replaced every 3-4 days. Adherent cells were sub-cultured by detachment with $0.25 \%$ trypsin (containing 0.02\% EDTA; Sigma-Aldrich) when they were $80-90 \%$ confluent. Cells of passage three were used in the subsequent experiments. The study was approved by the ethics committee of Jilin University (Changchun, China).

Induction of differentiation into insulin-secreting cells. rAdSCs of the third passage and of $80 \%$ confluency were used for induction of differentiation. The cells were seeded into 24 -well plates at a density of $1 \times 10^{5} /$ well and were divided into an induction group and a control group. The induction group was cultured in DMEM containing $20 \mathrm{ng} / \mathrm{ml}$ epidermal growth factor (Invitrogen Life Technologies, Inc.) for $24 \mathrm{~h}$ at $37^{\circ} \mathrm{C}$ in a humidified atmosphere containing $5 \% \mathrm{CO}_{2}$ and then supplemented with serum-free DMEM containing $10 \mathrm{mM}$ niacinamide (Sigma-Aldrich) and $100 \mathrm{nM}$ glucagon-like peptide (GLP-1; Sigma-Aldrich) followed by 21 days of culture. The media were replaced every three days. The control group was cultured in serum-free DMEM without niacinamide or GLP-1.

Dithizone (DTZ) staining. DTZ (ADL) stock solution was prepared by dissolving $10 \mathrm{mg}$ DTZ in $1 \mathrm{ml}$ of dimethyl sulfoxide (Sigma-Aldrich). The staining solution was filtered through a $0.2-\mathrm{mm}$ filter, and for in vitro DTZ staining, $10 \mu \mathrm{l}$ stock solution was added to $1 \mathrm{ml}$ culture medium. The cells of the induction and control groups were incubated at $37^{\circ} \mathrm{C}$ for $25 \mathrm{~min}$ in the DTZ solution. After the cells were rinsed three times with PBS, crimson red-stained clusters were observed under an X51 inverted light microscope (Olympus, Tokyo, Japan).

As positive control cells, pancreatic matrix cells of rabbits were used. Briefly, rabbit pancreatic tissue was isolated from an adult New-Zealand rabbit. The tissue was washed twice with an equal volume of sterile D-Hanks solution (Sigma-Aldrich) after excision. Washed tissue fragments were digested with $0.075 \%$ collagenase II (Sigma-Aldrich) for $30 \mathrm{~min}$ at $37^{\circ} \mathrm{C}$ and then centrifuged at 1,200 xg for $10 \mathrm{~min}$. Subsequently, the collected cells were filtered through a $100-\mu$ m cell strainer (Greiner Bio-One, Kremsmünster, Austria) and incubated at $37^{\circ} \mathrm{C}$ for $25 \mathrm{~min}$ in the DTZ solution as a positive staining control. After the cells were rinsed three times with PBS, crimson red-stained clusters were observed under an X51 inverted light microscope (Olympus, Tokyo, Japan).
RNA extraction and reverse transcription polymerase chain reaction $(R T-P C R)$ analysis. Total RNA was isolated from undifferentiated rAdSCs (negative control), human beta-cells (positive control; Shanghai Institute for Biological Sciences, Shanghai, China) and differentiated rAdSCs at the final stage of induction using TRIzol reagent (Invitrogen Life Technologies). RT was performed with $5 \mu \mathrm{g}$ of total RNA purified after DNAse I treatment using a commercially available RT-PCR kit (Takara Bio Inc., Otsu, Japan) according to the manufacturer's instructions. According to the GenBank database (http://www. ncbi.nlm.nih.gov/genbank) entries for the cDNA sequences of insulin, PDX1 and GLUT2, corresponding primers were designed and synthesized by Shanghai Biological Engineering Company (Shanghai, China). For insulin, the forward primer was 5'-ATCAAGCAGATCACTGTCCTTCT-3' and the reverse primer was 5'-GAGAGCTTCCACCAGGTGTG-3'. The PCR mixture (Takara Biotechnology Co., Ltd., Dalian, China) contained cDNA $(4 \mu \mathrm{l}), 25 \mathrm{mM}$ desoxyribonucleotide triphosphates $(1 \mu \mathrm{l}), 10 \mathrm{X}$ PCR buffer $(5 \mu \mathrm{l})$, forward and reverse primer $(50 \mathrm{pmol} ; 2 \mu \mathrm{l})$, Taq enzyme (1 U; $2.0 \mu \mathrm{l})$ and double-distilled $\mathrm{H}_{2} \mathrm{O}(34 \mu \mathrm{l})$. The conditions for PCR were as follows: $94^{\circ} \mathrm{C}$ for $3 \mathrm{~min} ; 30$ cycles of $94^{\circ} \mathrm{C}$ for $20 \mathrm{sec}, 62^{\circ} \mathrm{C}$ for $20 \mathrm{sec}, 72^{\circ} \mathrm{C}$ for $30 \mathrm{sec}$, and a final elongation at $72^{\circ} \mathrm{C}$ for $5 \mathrm{~min}$. PDX1 primers were as follows: Forward, 5'-TCCCATGGATGAAGTCTACC-3' and reverse, 5'-TGTCCTCCTCCTTTTTCCAC-3'. The components of the PCR mixture were the same as those above. The PCR conditions were as follows: 30 cycles of $94^{\circ} \mathrm{C}$ for $30 \mathrm{sec}$, $60^{\circ} \mathrm{C}$ for $30 \mathrm{sec}$ and $72^{\circ} \mathrm{C}$ for $30 \mathrm{sec}$, and a final elongation at $72^{\circ} \mathrm{C}$ for $5 \mathrm{~min}$. GLUT2 primers were as follows: Forward, 5'-AGTACAATGACAGAAGATAAGGTC-3' and reverse, 5'-AGCTCCAACTAATGACAGAATG-3'. The components of the PCR mixture were the same to those above. The PCR conditions were as follows: 32 cycles of $94^{\circ} \mathrm{C}$ for $30 \mathrm{sec}, 56^{\circ} \mathrm{C}$ for $30 \mathrm{sec}$ and $72^{\circ} \mathrm{C}$ for $1 \mathrm{~min}$, and a final elongation at $72^{\circ} \mathrm{C}$ for $5 \mathrm{~min}$. The PCR products were subjected to $1 \%$ agarose gel electrophoresis. GAPDH served as an internal reference to normalize the expression of the respective target genes. The GAPDH primers were as follows: Forward, 5'-GAAGGTGAAGGTCGGAGTC-3', and reverse, 5'-GAAGATGGTGATGGGATTTC-3'. The PCR conditions were as follows: 32 cycles of $94^{\circ} \mathrm{C}$ for $30 \mathrm{sec}, 56^{\circ} \mathrm{C}$ for $30 \mathrm{sec}$ and $72^{\circ} \mathrm{C}$ for $1 \mathrm{~min}$, and a final elongation at $72^{\circ} \mathrm{C}$ for $5 \mathrm{~min}$. Gel images were analyzed using the UVI band map program (Uvitec, Cambridge, UK). Gel images were observed under a AB1 Veriti Gel Imaging Analysis system (Applied Biosystems Life Technologies, Foster City, CA, USA) and were analyzed using an UVI Band Map program (Uvitec, Cambridge, UK). The experiments were repeated thrice and a $t$-test was employed for analysis.

Western blot analysis. Total protein was extracted from undifferentiated AdSCs (negative control), human beta-cells (positive control) and differentiated AdSCs at the final stage of induction on day 21 were lysed in radioimmunoprecipitation assay buffer (Sigma-Aldrich) containing $10 \mathrm{mM}$ Tris- $\mathrm{HCl}$ (pH 8.0), 1\% NP-40, 10\% glycerol, 0.1\% SDS, 1 mM EDTA and $100 \mathrm{mM} \mathrm{NaCl}$ with protease inhibitor cocktail (Roche Diagnostics, Basel, Switzerland). The protein concentration was determined using the bicinchoninic acid protein assay 
$\mathbf{A}$
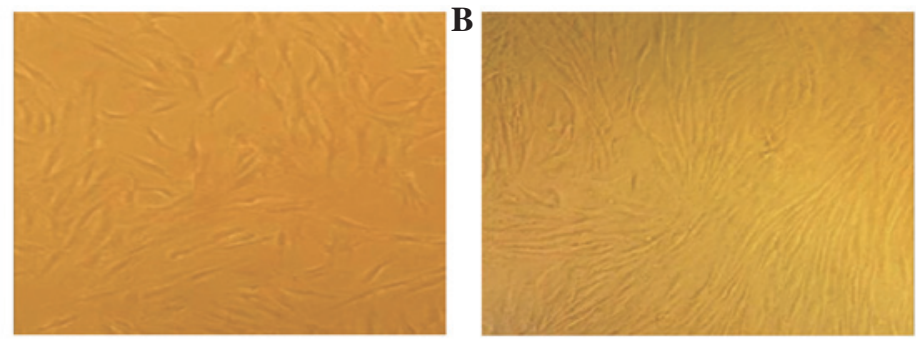

Figure 1. Morphological changes of rAdSC differentiation. (A) rAdSCs were spindle-shaped and fibroblast-like prior to induction of differentiation. (B) Morphological changes of differentiated rAdSCs after 14 days of induction. rAdSCs, adipose tissue-derived stromal cells. Magnification, x100.

A

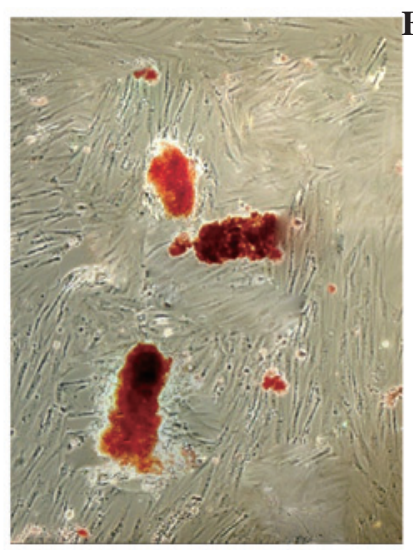

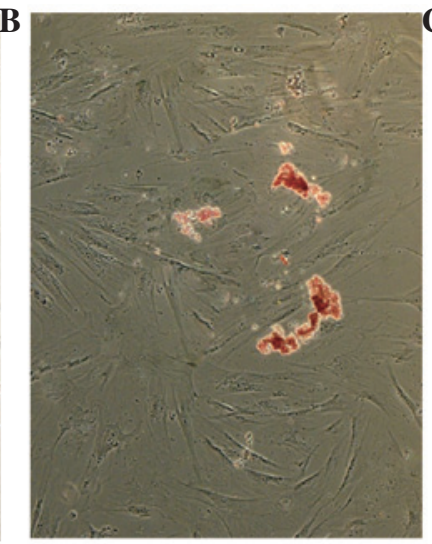

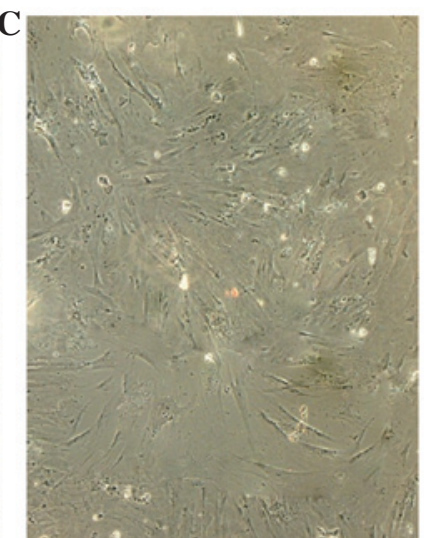

Figure 2. Histochemical analysis of rAdSCs on day 21 of differentiation by dithizone staining for insulin. (A) Pancreatic matrix cells were selectively stained as positive control cells. The image shows a positive cell cluster. (B) Crimson red-stained clusters indicate insulin positivity in differentiated rAdSCs. (C) Negative control rAdSCs, rAdSCs, adipose tissue-derived stromal cells.

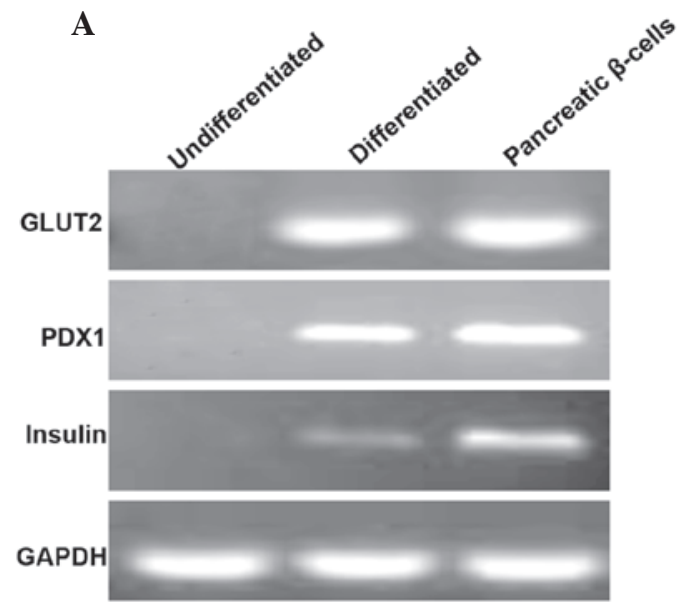

B

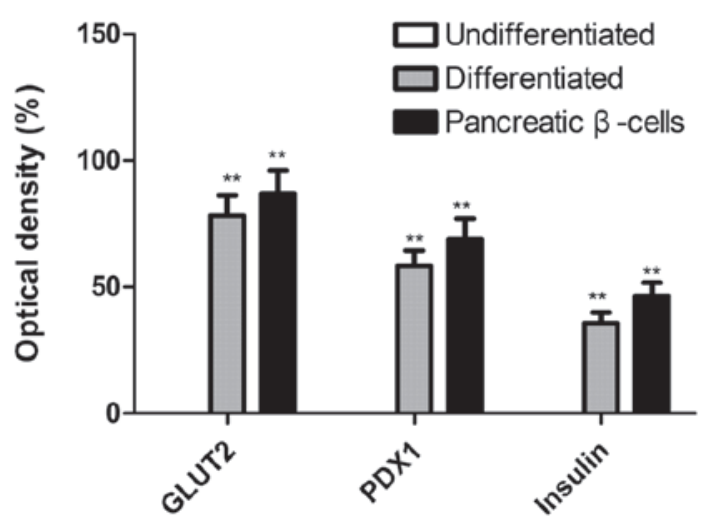

Figure 3. Reverse transcription polymerase chain reaction analysis of differentiation-associated genes in undifferentiated rAdSCs, differentiated rAdSCs, and pancreatic $\beta$-cells. (A) The gel is representative of three repetitions. (B) Quantification of GLUT2, PDX1 and insulin expression by optical density. ${ }^{* *} \mathrm{P}<0.01$ vs. undifferentiated rAdSCs. rAdSCs, rabbit adipose tissue-derived stromal cells; GLUT2, glucose transporter 2; PDX1, pancreatic and duodenal homeobox 1.

kit (KeyGEN Biotech, Nanjing, China). Equal amounts of protein $(30 \mu \mathrm{g} /$ lane $)$ from the cell lysates were separated by $10 \%$ SDS-PAGE and transferred onto nitrocellulose membranes (Santa Cruz Biotechnology, Inc., Dallas, TX, USA). The membrane was incubated for $2 \mathrm{~h}$ in PBS containing 0.1\% Tween-20 (Sigma-Aldrich) and 5\% skimmed milk (Sigma-Aldrich) to block non-specific binding. The membranes were then incubated overnight at $4^{\circ} \mathrm{C}$ with mouse polyclonal anti-rabbit insulin (1:1,000; cat. no. sc-9168; Santa Cruz Biotechnology, Inc.). Mouse polyclonal anti-human GAPDH (1:10,000; cat. no. sc-25778; Santa Cruz Biotechnology, Inc.) was used as a loading control. The membranes were incubated with polyclonal goat anti-mouse horseradish peroxidase-conjugated secondary antibody (1:10,000; cat. no. sc-2004; Santa Cruz Biotechnology, Inc.) at room temperature for $2 \mathrm{~h}$, and proteins were detected by enhanced chemiluminescence 
A

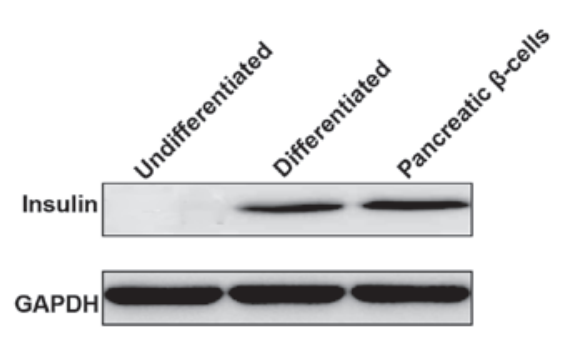

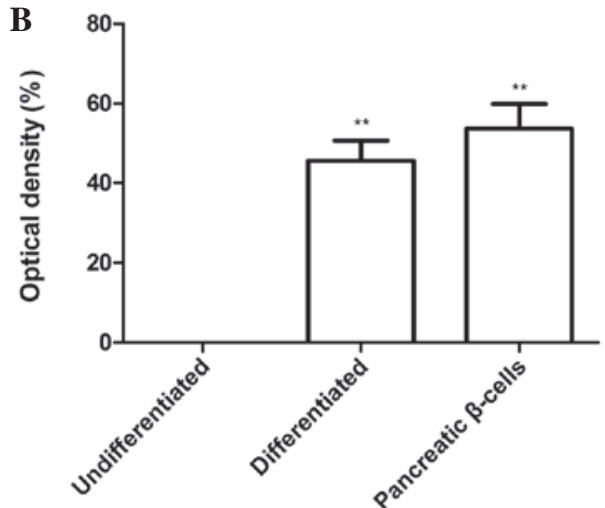

Figure 4. Detection of insulin protein synthesis by western blot analysis in undifferentiated rAdSCs, differentiated rAdSCs and pancreatic $\beta$-cells. (A) Western blot analysis of insulin expression. (B) Quantification of insulin expression by optical density. ${ }^{* *} \mathrm{P}<0.01$ vs. undifferentiated rAdSCs. rAdSCs, rabbit adipose tissue-derived stromal cells.

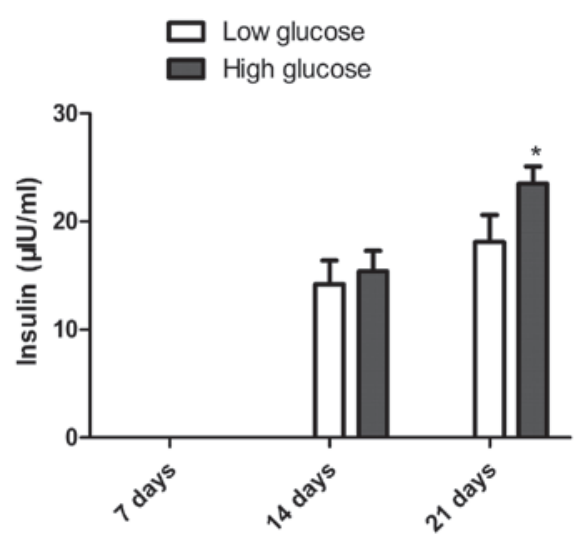

Figure 5. In vitro glucose response assay of rabbit adipose tissue-derived stromal cells induced to differentiate into insulin-producing cells for various durations. Insulin secreted in cultured media in response to low glucose $(10 \mathrm{mM})$ and high glucose $(30 \mathrm{mM})$ following $24 \mathrm{~h}$ of incubation was detected by ELISA. Values are expressed as the mean \pm standard deviation $(\mathrm{n}=3) .{ }^{*} \mathrm{P}<0.05$ compared to low glucose $(10 \mathrm{mM})$.

western blotting detection system (Thermo Fisher Scientific, Waltham, MA, USA), and were analyzed using image analysis software ImageJ 3.1 (Bio-Rad Laboratories, Inc., Hercules, CA, USA).

Glucose challenge assay. The cell density of differentiated rAdSCs was adjusted to $1 \times 10^{5} / \mathrm{ml}$, cells were seeded into a 24-well plate (100 $\mu \mathrm{l} /$ well) and wells were divided into LG group and high-glucose (HG) group (24 wells per group). Undifferentiated rAdSCs were used as a control group. Following differentiation of the cells for 7, 14 and 21 days, the LG group and HG group were established by adding DMEM containing $10.0 \mathrm{mmol} / \mathrm{l}$ glucose and DMEM containing $30.0 \mathrm{mmol} / 1$ glucose, respectively, followed by $24 \mathrm{~h}$ of incubation. Then insulin production was measured in the cell supernatants using rabbit insulin ELISA kits (Invitrogen Life Technologies, Inc.).

Statistical analysis. Values are expressed as the mean \pm standard deviation of data from at least three independent experiments. Student's $t$-test and one-way analysis of variance were used with the level of significance set as $\mathrm{P}<0.05$. All data were analyzed using GraphPad Prism version 5.01 for Windows $^{\circledR}$ (GraphPad Software, Inc., La Jolla, CA, USA).

\section{Results}

rAdSCs undergo morphological changes during differentiation. During differentiation, morphological changes of rAdSCs were observed under a phase contrast inverted microscope. Prior to differentiation, the rAdSCs exhibited a typical stromal cell-like morphology (Fig. 1A). Of note, upon differentiation, the cells began to contract, the ecphyma became shorter, and the morphology changed from spindle-like to a round shape (Fig. 1B).

rAdSCs differentiate into insulin-producing, cluster-forming cells. The present study identified IPCs by DTZ staining. Regions of pancreatic endocrine cells in culture can be specifically labeled, since beta-cells in the islet contain a large amount of zinc, which can be specifically labeled with the zinc-chelating dye DTZ (16-18). As shown in Fig. 2A, pancreatic endocrine cells (positive control) were distinctly stained crimson red by DTZ. Furthermore, rAdSCs in the induction group were distinctly stained crimson red by DTZ at the final step of differentiation on day 21 (Fig. 2B), while undifferentiated cells (negative control) were negative for DTZ (Fig. 2C).

rAdSCs are able to differentiate into insulin-producing pancreatic endocrine cells. To determine whether the rAdSCs had differentiated into pancreatic endocrine cells, the expression of genes associated with pancreatic endocrine-cell development and function, including the mRNA expression of insulin, PDX1 and GLUT2, were examined by RT-PCR analysis. The results showed that insulin, PDX1 and GLUT2 were expressed in human beta-cells (positive control) as well as in differentiated AdSCs at the final stage of induction, while negative expression was observed in undifferentiated cells (negative control) (Fig. 3A and 3B).

To confirm the insulin expression of the IPCs at the protein level, western blot analysis was performed. It was found that insulin protein was expressed in human beta-cells (positive control) as well as in differentiated AdSCs, while undifferentiated AdSCs did not express any insulin (Fig. 4A and 4B). In 
addition, insulin protein in beta-cells was markedly higher than that of differentiated AdSCs (Fig. 4B). All of the above results indicated that AdSCs possess the potential to differentiate into functional IPCs.

Measurement of insulin production of glucose challenge assay. To quantify the insulin production of AdSC-derived IPCs following glucose challenge, an ELISA assay was performed. Insulin expression was negative in the $\mathrm{HG}$ and LG groups after 7 days of differentiation. While insulin was detected in the culture supernatant of AdSCs induced to differentiate for 14 days, there was no significant difference in insulin production between the LG group $(14.2 \pm 2.2 \mu \mathrm{IU} / \mathrm{ml})$ and the HG group $(15.4 \pm 1.9 \mu \mathrm{IU} / \mathrm{ml})(\mathrm{P}>0.05$; Fig. 5). Of note, insulin production was increased in the two groups after 21 days of differentiation, with insulin production in the $\mathrm{HG}$ group $(23.5 \pm 1.6 \mu \mathrm{IU} / \mathrm{ml})$ being significantly higher than that in the LG group $(18.1 \pm 2.5 \mu \mathrm{IU} / \mathrm{ml})(\mathrm{P}<0.05$, Fig. 5). The control cells did not exhibit any insulin production at the indicated time-points (results not shown).

\section{Discussion}

A number of previous studies have demonstrated the potential of MSCs obtained from various sources in the treatment of DM $(19,20)$. AdSCs share a number of characteristics with BMSCs (12); therefore, AdSCs have become another hot-spot in the field of stem cell research besides BMSCs. Zuk et al (21) verified that AdSCs can be isolated from human lipoaspirates and differentiate toward osteogenic, adipogenic, myogenic and chondrogenic lineages. A recent study showed that adipose-derived MSCs were able to differentiate into IPCs in vitro by induction with $\beta$-mercaptoethanol and nicotinamide (22). Consistent with this result, the present study showed that rAdSCs differentiated into IPCs following induction with GLP-1 and nicotinamide.

Numerous studies have provided protocols for the efficient transdifferentiation of stem cells into IPCs, with varying degrees of successful differentiation $(12,22)$. In order to successfully achieve differentiation of stem cells into IPCs the key point is to select suitable inductive agents and to optimize the hemopoietic inductive in vitro microenvironment, which should resemble the conditions in the body. GLP-1 is a peptide hormone, which is produced post-translationally from pro-glucagon genes; GLP-1 stimulates insulin gene translation and insulin biosynthesis, promotes the differentiation and generation of insulin-excreting precursor cells (23), stimulates the generation and differentiation of $\beta$ cells and reduces their apoptosis (24). PDX-1 is the main controlling gene in growth of pancreatic endocrine cells; it promotes early development of pancreatic cells and the advanced differentiation of $\beta$ cells (25). GLP-1 is able to regulate gene expression via multiple signaling pathways, promote the synthesis of PDX-1 and increase the binding activity of PDX-1 to promoters (26). It has been shown that GLP-1 is able to induce stem-cell differentiation into islets cells with a high differentiation induction rate (26). The results of the present study showed that AdSCs were able to differentiate into IPCs by induction with DMEM supplemented with GLP-1 and nicotinamide.
Niacinamide is an inhibitor of adenosine diphosphate ribose synthesis, which can promote the differentiation of pancreatic cells in human fetuses, as well as maintain normal responses of islet cells to glucose stimulation in a $\mathrm{HG}$ environment over a long time period (27). Therefore, niacinamide is widely used as a constitutive component of induction media for the differentiation of stem cells into IPCs (28). The results of the present study showed that GLP-1 in combination with niacinamide successfully induced the differentiation of AdSCs into IPCs.

Although the present study showed that rAdSCs were able to differentiate into IPCs, their insulin secretion was far lower than that of normal human pancreatic islet cells, which may have been due to the fact that the rAdSCs had not been selected thoroughly enough. Lower insulin production may also have been due to incomplete differentiation, and further studies should further optimize the differentiation conditions Molecular markers of islet stem cells are of high significance for the identification and purification from the mass of other cells. While no specific marker is currently available, purified clones from insulin-secreting stem cells may be employed, which should be developed in future studies.

\section{Acknowledgements}

The authors gratefully acknowledge the financial support provided by the Science and Technology Research and Innovation Team funded by Jilin province (no. JL2012058).

\section{References}

1. Gao D, Xie J, Zhang J, Feng C, Yao B, Ma K, Li J, Wu X, Huang S and $\mathrm{Fu} \mathrm{X}$ : MSC attenuate diabetes-induced functional impairment in adipocytes via secretion of insulin-like growth factor-1. Biochem Biophys Res Commun 452: 99-105, 2014.

2. American Diabetes A: Diagnosis and classification of diabetes mellitus. Diabetes Care 36 (Suppl 1): S67-S74, 2013.

3. Shaw JE, Sicree RA and Zimmet PZ: Global estimates of the prevalence of diabetes for 2010 and 2030. Diabetes Res Clin Pract 87: 4-14, 2010.

4. Chen LB, Jiang XB and Yang L: Differentiation of rat marrow mesenchymal stem cells into pancreatic islet beta-cells. World J Gastroenterol 10: 3016-3020, 2004.

5. Oh SH, Muzzonigro TM, Bae SH, LaPlante JM, Hatch HM and Petersen BE: Adult bone marrow-derived cells trans-differentiating into insulin-producing cells for the treatment of type I diabetes. Lab Invest 84: 607-617, 2004.

6. Vija L, Farge D, Gautier JF, Vexiau P, Dumitrache C, Bourgarit A, Verrecchia $\mathrm{F}$ and Larghero J: Mesenchymal stem cells: Stem cell therapy perspectives for type 1 diabetes. Diabetes Metab 35: 85-93, 2009.

7. Wu XH, Liu CP, Xu KF, Mao XD, Zhu J, Jiang JJ, Cui D, Zhang M, $\mathrm{Xu}$ Y and Liu C: Reversal of hyperglycemia in diabetic rats by portal vein transplantation of islet-like cells generated from bone marrow mesenchymal stem cells. World J Gastroenterol 13: 3342-3349, 2007.

8. Nejad-Dehbashi F, Hashemitabar M, Orazizadeh M, Bahramzadeh S, Shahhosseini Pourshoushtary E and Khorsandi L: The effects of exendine- 4 on insulin producing cell differentiation from rat bone marrow-derived mesenchymal stem cells. Cell J 16: 187-194, 2014.

9. Zhang YH, Wang HF, Liu W, Wei B, Bing LJ and Gao YM: Insulin-producing cells derived from rat bone marrow and their autologous transplantation in the duodenal wall for treating diabetes. Anat Rec (Hoboken) 292: 728-735, 2009.

10. Gimble JM, Katz AJ and Bunnell BA: Adipose-derived stem cells for regenerative medicine. Circ Res 100: 1249-1260, 2007.

11. Pittenger MF, Mackay AM, Beck SC, Jaiswal RK, Douglas R, Mosca JD, Moorman MA, Simonetti DW, Craig S and Marshak DR: Multilineage potential of adult human mesenchymal stem cells. Science 284: 143-147, 1999. 
12. Noël D, Caton D, Roche S, Bony C, Lehmann S, Casteilla L, Jorgensen C and Cousin B: Cell specific differences between human adipose-derived and mesenchymal-stromal cells despite similar differentiation potentials. Exp Cell Res 314: 1575-1584, 2008

13. Tyndall A, Walker UA, Cope A, Dazzi F, De Bari C, Fibbe W, Guiducci S, Jones S, Jorgensen C, Le Blanc K, et al: Immunomodulatory properties of mesenchymal stem cells: A review based on an interdisciplinary meeting held at the Kennedy Institute of Rheumatology Division, London, UK, 31 October 2005. Arthritis Res Ther 9: 301, 2007.

14. Krampera M, Pasini A, Pizzolo G, Cosmi L, Romagnani S and Annunziato F: Regenerative and immunomodulatory potential of mesenchymal stem cells. Curr Opin Pharmacol 6: 435-441, 2006.

15. Takahara K, Ii M, Inamoto T, Komura K, Ibuki N, Minami K, Uehara H, Hirano H, Nomi H, Kiyama S, et al: Adipose-derived stromal cells inhibit prostate cancer cell proliferation inducing apoptosis. Biochem Biophys Res Commun 446: 1102-1107, 2014.

16. Li L, Li F, Qi H, Feng G, Yuan K, Deng H and Zhou H: Coexpression of Pdx 1 and betacellulin in mesenchymal stem cells could promote the differentiation of nestin-positive epithelium-like progenitors and pancreatic islet-like spheroids. Stem Cells and Dev 17: 815-823,2008.

17. Bruin JE, Erener S, Vela J, Hu X, Johnson JD, Kurata HT, Lynn FC, Piret JM, Asadi A, Rezania A and Kieffer TJ Characterization of polyhormonal insulin-producing cells derived in vitro from human embryonic stem cells. Stem Cell Res 12: 194-208, 2014.

18. Wei R, Yang J, Hou W, Liu G, Gao M, Zhang L, Wang H, Mao G, Gao H, Chen G and Hong T: Insulin-producing cells derived from human embryonic stem cells: Comparison of definitive endoderm- and nestin-positive progenitor-based differentiation strategies. PloS one 8: e72513, 2013.

19. Gao F, Wu DQ, Hu YH, Jin GX, Li GD, Sun TW and Li FJ: In vitro cultivation of islet-like cell clusters from human umbilical cord blood-derived mesenchymal stem cells. Transl Res 151: 293-302, 2008.
20. Chandra V, Swetha G, Muthyala S, Jaiswal AK, Bellare JR, Nair PD and Bhonde RR: Islet-like cell aggregates generated from human adipose tissue derived stem cells ameliorate experimental diabetes in mice. PloS one 6: e20615, 2011.

21. Zuk PA, Zhu M, Ashjian P, De Ugarte DA, Huang JI, Mizuno H, Alfonso ZC, Fraser JK, Benhaim P and Hedrick MH: Human adipose tissue is a source of multipotent stem cells. Mol Biol Cell 13: 4279-4295, 2002.

22. Moshtagh PR, Emami SH and Sharifi AM: Differentiation of human adipose-derived mesenchymal stem cell into insulin-producing cells: An in vitro study. J Physiol Biochem 69: 451-458, 2013.

23. Bregenholt S, Møldrup A, Blume N, Karlsen AE, Nissen Friedrichsen B, Tornhave D, Knudsen LB and Petersen JS: The long-acting glucagon-like peptide-1 analogue, liraglutide, inhibits beta-cell apoptosis in vitro. Biochem Biophys Res Commun 330: 577-584, 2005.

24. Hui H, Nourparvar A, Zhao X and Perfetti R: Glucagon-like peptide-1 inhibits apoptosis of insulin-secreting cells via a cyclic 5'-adenosine monophosphate-dependent protein kinase Aand a phosphatidylinositol 3-kinase-dependent pathway. Endocrinology 144: 1444-1455, 2003.

25. Li LX, MacDonald PE, Ahn DS, Oudit GY, Backx PH and Brubaker PL: Role of phosphatidylinositol 3-kinasegamma in the beta-cell: Interactions with glucagon-like peptide-1. Endocrinology 147: 3318-3325, 2006.

26. Wang X, Zhou J, Doyle ME and Egan JM: Glucagon-like peptide-1 causes pancreatic duodenal homeobox-1 protein translocation from the cytoplasm to the nucleus of pancreatic beta-cells by a cyclic adenosine monophosphate/protein kinase A-dependent mechanism. Endocrinology 142: 1820-1827, 2001.

27. Ji D, Li GY and Osborne NN: Nicotinamide attenuates retinal ischemia and light insults to neurones. Neurochem Int 52: 786-798, 2008

28. Yang SJ, Choi JM, Kim L, Park SE, Rhee EJ, Lee WY, Oh KW, Park SW and Park CY: Nicotinamide improves glucose metabolism and affects the hepatic NAD-sirtuin pathway in a rodent model of obesity and type 2 diabetes. J Nutr Biochem 25: 66-72, 2014. 